\title{
REVERSAL OF RENAL ALLOGRAFT REJECTION WITH INTRAVENOUS METHYLPREDNISOLONE "PULSE" THERAPY
}

\author{
NIGHOLAS J. FEDUSKA, M.D., JERHMiAH G. 'IURCO'N'IE, M.D., PAUt. W. GLKAS, M.D., \\ GEORGE E. BACON, M.D., AND JOHN A. PENNER, M.D.
}

\section{REJECTION CONTINUES TO BE A} MAJOR PROBLEM confronting the transplant recipient and his surgeon. Acute rejection of renal allografts is commonly treatied hy increasing the daily oral dose of corticosteroids. Multiple complications of this therapy, including gastrointestinal hemorrhage and increased susceptibility to infection, have been reported. Intermittent large-dose intravenous corticosteroid therapy has the theoretical, but still unproved, potential of halting rejection while avoiding the toxicity associated with frequent oral administration. Intravenous corticosteroid therapy has been used by some clinicians to treat rejection $[2,4]$. However, many clinical transplant teams have not been convineed of the advantages of the intravenous route and have continued to treat rejection by increasing the oral dose of corticosteroids to $200-300 \mathrm{mg}$./day usually given in divided doses. A recent toxicologic study demonstrated that an even larger intravenous dose of

From the Section of General Surgery and the Departments of Pathology, Pediatrics, Pharmacology, and Internal Medicine, University of Michigan Medical Center, Ann Arbor, Michigan 48104.

This study was supported by the Maude T. Lane Fund, Upjohn Transplantation Fund, USPHS Grants 5-TO1-HE-05526-07 and 5-P11-GM-15559, and the Michigan Heart Association.

The authors are indebted to the Upjohn Company, Kalamazoo, Michigan, for supplies of methylprednisolone sodium succinate (Solu-Medrol).

Address for reprints: Jeremiah G. Turcotte, M.D. Section of General Surgery, University of Michigan Medical Center, Ann Arbor, Michigan 48104.

Presented before the Association for Academic Surgery, 5th Annual Meeting, Philadelphia, Nov. 19, 1971.

Submitted for publication Dec. 15, 1971. methylprednisolone sodium succinate, than has been used to treat rejection previously, is well tolerated by humans [9]. Our study deals with the use of very large intravenous doses of methylprednisolone, that is $30 \mathrm{mg} . / \mathrm{kg}$, for treating allograft rejection in dogs and humans. In addition, the circulating half-life of methylprednisolone using a highly specific gas chromatographic method was defined for the first time [1]. The notable absence of serious side effects, probably related to the relatively short circulating half-life of this drug when administered intravenously, and the ability of this dosage regimen to modify allograft rejection are documented in this study.

\section{MATERIALS AND METHODS}

\section{Animal Studies}

Fourteen beagles underwent bilateral recipient nephrectomy and received renal allografts. Urine was collected in metabolic cages. Serial hemalulugic, coagulation, and blood and urine studies were obtained. Endogenous creatinine, inulin, and para-aminohippurate (PAH) clearances were determined. Serial biopsies were taken of the kidney allograft, spleen, mesenteric lymph nodes, and liver. Sections of these tissues were examined using hematoxylin-eosin and methyl green pyronin stains [7]. All studies were not obtained in every dog. Serial renal arteriograms were performed before and after rejection in four dogs. No technical problems or other operative complications were encountered. All kidneys functioned promptly and serum creatinine was less than $1.2 \mathrm{mg} . / 100 \mathrm{ml} .24$ hours after transplantation 
in all animals. Subscquent elevation of serum creatinine to $2.0 \mathrm{mg} . / 100 \mathrm{ml}$. or higher was interpreted as reflecting the onset of acute rejection. Each dog was then treated with an intravenous "pulse" of methylprednisolone, 30 mg. $/ \mathrm{kg}$., administered in $500 \mathrm{ml}$. of $5 \%$ dextrose in $0.2 \% \mathrm{NaCl}$ over 1 hour. To substantiate the diagnosis of rejection an open renal biopsy was performed just prior to administering the pulse in 10 dogs. Frequent serum levels of methylprednisolone were determined using gas chromatography as described by Bacon during the 24 hours after administration of the pulse [1]. Serial studies were continued until death at which time an autopsy was performed upon all dogs.

One additional dog with a renal allograft was treated with four consecutive daily pulses of methylprednisolone $30 \mathrm{mg}$. $/ \mathrm{kg}$. In this dog open renal biopsies were taken at the time of transplantation, immediately prior to each pulse and at autopsy.

Similar serial blood and urine studies were obtained in six control dogs. Four dogs were used to study the toxicology of intravenous methylprednisolone; two dogs received $\mathbf{1 5}$ $\mathrm{mg} . / \mathrm{kg}$, and two received $30 \mathrm{mg} . / \mathrm{kg}$. Two other dogs served as untreated controls; that is, they underwent bilateral recipient nephrectomy, received renal allografts, and were studied serially, but were not treated for rejection with methylprednisolone. A seventh dog also served as an untreated control. This animal underwent bilateral recipient nephrectomy, received a renal allograft, and underwent serial open renal biopsies at the same times after transplantation as the dog treated with four consecutives pulses. Rejection in this dog, however, was not treated with methylprednisolone.

\section{Human Studies}

The records of 100 consecutive recipients of human renal allotransplants performed at the University of Michigan Medical Center between June 18, 1969 and Oct. 20, 1971 werc reviewed and acute rejection episodes were identified. These episodes were defined as those occasions when an abrupt deterioration in renal function occurred in the absence of other possible explanations such as technical or infectious complications. Often other signs of rejection were present. These rejection episodes were treated with single or multiple pulses of intravenous methylprednisolone 30 $\mathrm{mg}$. $\mathrm{kg}$. given in $200 \mathrm{ml}$. of $5 \%$ dextrose in water over one-half hour. A pulse was repeated every 48-72 hours for a maximum of three or four doses as needed to reverse rejection. In most cases, the daily oral maintenance dose of prednisone was also raised slightly, that is, the maintenance dose was increased by $25 \%$ or $10 \mathrm{mg}$., whichever was larger.

\section{RESULTS}

\section{Animal Studies}

Elevation of serum creatinine to $2.0 \mathrm{mg}$. $/ 100$ $\mathrm{ml}$. or higher, reflecting the onset of acute rejection, occurred $6.2 \pm 0.7$ days after transplantation. The mean survival of dogs treated with a single pulse was $9.6 \pm 0.3$ days. This did not differ significantly when compared with untreated control dogs. No clinicul evidence of toxicity from the pulse, such as gastrointestinal bleeding, was observed in any dog.

\section{Hematologic, Coagulation, Blood, and Urine Chemistry Studies}

No significant changes or biochemical evidence of toxicity consequent to methylprednisolone pulse therapy were demonstrated in serial studies of hematocrit, white blood cell count, relative and absolute lymphocyte counts; platelet count; prothrombin time; partial thromboplastin time; thrombin clotting time; quantitative fibrinogen levels; serum creatinine; blood urea nitrogen; serum sodium, potassium, chloride, carbon dioxide, and magnesium; bilirubin; serum glutamic oxalacetic transaminase; total serum protein and albumin; or urine sodium, potassium, chloride and magnesium. The changes in blood studies observed in dogs treated with a pulse while undergoing rcjection were similar to changes ubserved in untreated animals during rejection. The only changes observed in the four dogs not operated upon which received either $15 \mathrm{or}^{\circ}$ $30 \mathrm{mg} . / \mathrm{kg}$. methylprednisolone intravenously was a rise in total white blood cell count and a 
Table 1. Endogenous Creatinine Clearance in Liters/24 Hours

\begin{tabular}{crrrc}
\hline Dog & $\begin{array}{c}\text { Day } \\
\text { Prior to } \\
\text { "Pulse" }\end{array}$ & $\begin{array}{c}\text { Day of } \\
\text { "Pulse" }\end{array}$ & $\begin{array}{c}\text { 1 Day } \\
\text { After } \\
\text { "Pulse" }\end{array}$ & $\begin{array}{c}\text { 2 Days } \\
\text { After } \\
\text { "Pulse" }\end{array}$ \\
\hline SMH-1 & 18.7 & 6.3 & 2.3 & 2.6 \\
SMH-2 & 20.6 & 3.6 & 1.4 & 3.2 \\
SMH-3 & 14.0 & 12.9 & 4.0 & - \\
SMH-4 & 13.0 & 7.0 & 11.0 & - \\
SMH-6 & - & 2.6 & 1.5 & 1.2 \\
SMH-8 & 28.9 & 9.4 & 8.5 & $\mathbf{5 . 6}$ \\
Mean & 19.0 & 7.0 & 4.8 & 3.2 \\
SD & \pm 6.3 & \pm 3.8 & \pm 3.3 & \pm 1.8 \\
\hline
\end{tabular}

Table 2. Glomerular Filtration Rate as Determined by Inulin Clearance in Milliliters per Minute.

\begin{tabular}{lrrr}
\hline Dog & $\begin{array}{r}\text { Day of } \\
\text { "Pulse" }\end{array}$ & $\begin{array}{c}\text { 1 Day } \\
\text { After } \\
\text { "Pulse" }\end{array}$ & $\begin{array}{c}\text { 2 Days } \\
\text { After } \\
\text { "Pulse" }\end{array}$ \\
\hline SMH-3C & 2.5 & 2.7 & 4.1 \\
SMH-4C & 4.8 & 8.0 & 3.8 \\
SMH-6C & 0.9 & 2.2 & 1.6 \\
Mean & 2.7 & 4.3 & 3.2 \\
SU & \pm 2.0 & \pm 3.2 & \pm 1.4 \\
\hline
\end{tabular}

marked reduction in absolute lymphocyte count.

\section{Renal Clearance Studies and Renal Arterio- grams}

In six dogs endogenous creatinine clearance and in three dogs inulin and PAH clearance studies were obtained before and after pulse therapy. Creatinine clearance decreased precipilously in most dogs between the day prior to pulse therapy and the day of pulse administration confirming that the rejection process was very active at this time (Table 1). Pulse therapy seemed to halt this trend as indicated by modest improvements in creatinine clearance in three of six dogs, inulin clearance in all three dogs studied, and PAH clearance in two of three dogs (Tables 2 and 3). The serial renal arteriograms obtained during rejection showed the typical progressive changes of rejection. No improvement was demonstrated in the arteriographic appearance of rejection subsequent to pulse therapy.

\section{Serum $L D H$}

Serum LDH levels were elevated at the time of therapy for rejection (Table 4). LDH was reduced in five of nine dogs treated with intra- venous methylprednisolone and the moan LDH level of the entire group of nine dogs treated with pulse was also reduced. These changes in $\mathrm{LDH}$ did not reach statistical significance in this small group of animals.

\section{Total Urine LDH, Urine Volume, and Osmo- lality}

Total urine $\mathrm{LDH}$ was also elevated at the time of therapy for rejection (Table 4). Total urine $\mathrm{LDH}$ excretion was reduced in six of six dogs within 48 hours after administration of methylprednisolone. Twenty-four-hour urine volume was increased in all eight dogs within 48 hours after pulse therapy. The mean increase was $692 \mathrm{ml}$, and the least increase observed was $490 \mathrm{ml}$; in five dogs the magnitude

Table 3. Renal Plasma Flow as Determined by ParaAminohippurate Clearance in Milliliters per Minute

\begin{tabular}{lrrr}
\hline Dog & $\begin{array}{c}\text { Day of } \\
\text { "Pulse" }\end{array}$ & $\begin{array}{c}\text { 1 Day } \\
\text { After } \\
\text { "Pulse" }\end{array}$ & $\begin{array}{c}\text { 2 Days } \\
\text { After } \\
\text { "Pulse" }\end{array}$ \\
\hline SMH-3C & 8.3 & 3.1 & 7.4 \\
SMH-4C & 25.4 & 17.0 & 13.0 \\
SMH-6C & 2.6 & 4.1 & 2.9 \\
Mean & 12.1 & 8.1 & 7.8 \\
SD & +11.7 & +7.7 & \pm 5.1 \\
\hline
\end{tabular}

Table 4. Serial Serum LDH, Urine LDH, Urine Volume, and Urine Osmolality Studies*

\begin{tabular}{|c|c|c|c|}
\hline & $\begin{array}{c}\text { No. } \\
\text { of } \\
\text { Dogs }\end{array}$ & \begin{tabular}{|} 
Mean \pm Standard \\
Deviation at \\
Time of \\
Pulse
\end{tabular} & $\begin{array}{l}\text { Mean } \pm \text { Standard } \\
\text { Deviation Within } \\
48 \text { Hours } \\
\text { After Pulse }\end{array}$ \\
\hline \multicolumn{4}{|l|}{ Serum LDH } \\
\hline Treated & 9 & $467 \pm 378$ & $337 \pm 127$ \\
\hline Controls & 2 & $305 \pm 35$ & $355 \pm 21$ \\
\hline \multicolumn{4}{|l|}{ Urine LDH } \\
\hline Treated & 6 & $63,611 \pm 34,730$ & $24,964 \pm 20,440$ \\
\hline Controls & 2 & $34,973 \pm 29,450$ & $34,013 \pm 5,675$ \\
\hline \multicolumn{4}{|l|}{$\begin{array}{l}\text { Urine vol- } \\
\text { ume }\end{array}$} \\
\hline Treated & 8 & $332 \pm 186$ & $1024 \pm 395$ \\
\hline \multicolumn{4}{|l|}{$\begin{array}{l}\text { Urine os- } \\
\text { molality }\end{array}$} \\
\hline Treated & 6 & $299 \pm 115$ & $276 \pm 77$ \\
\hline Controls & 2 & $924 \pm 752$ & $449 \pm 211$ \\
\hline
\end{tabular}

* LDH activity is expressed in B-B units. Urine volume is recorded as milliliters per 24 hours and urine osmolality is milliosmoles/liter. Control animals received renal allografts, but were not treated with methylprednisolone. 
of the increase exceeded the $500-\mathrm{ml}$. volume of fluid administered intravenously as a vehicle for methylprednisolone. Urine osmolality dropped to a low level at the time of rejection, and in four dogs the urine osmolality increased within 48 hours after a single pulse. The standard deviations of these determinations were large and the numbers of animals relatively small; none of these changes in urine $\mathrm{LDH}$, urine volume, or osmolality reached statistical significance.

\section{Histology}

Histologic evidence of rejection was present in the allografts of all 10 dogs biopsied immediately prior to "pulse" therapy. A striking reduction in the cellular infiltrate was noted in 2 of 10 dogs biopsied 48 hours subsequent to "pulse" therapy (Figs. 1, 2, and 3). Both pyroninophilic and nonpyroninophilic cells were reduced. In biopsies taken at a later time the rejection process again progressed. In the other ejght doge biopsied after receiving a pulse no convincing improvement in the histology of rejection could be consistently substantiated in the multiple sections examined. Rejection proceeded relentlessly in the allografts of the two dogs which served as untreated controls; there was a progressive accumulation of py- roninophilic and nonpyroninophilic cellular infiltrate, necrosis of tubules and vessels, thrombosis of vessels, and multiple hemorrhagic infarcts.

In the dog receiving four pulses at 24 -hour intervals beginning on the fifth day after transplantation, a delayed but more sustained reduction of the cellular infiltrate in the renal allograft occurred. Significant reversal of the histologic pattern of rejection was first noted 24 hours after the third pulse. The dog died 24 hours after receiving the fourth pulse; this was 9 days after transplantation. The serum creatinine had remained below $1.0 \mathrm{mg} . / 100 \mathrm{ml}$. even in the sample drawn just shortly prior to death. A kidney biopsy taken at autopsy exhibited relatively mild focal infiltrates of mononuclear cells. The cause of death was not apparent, but a wound infection was present

Biopsies of spleen, mesenteric lymph nodes, and liver were taken in 10 dogs at the time of renal transplantation, time of pulse treatment, 48 hours subsequent to pulse, and at autopsy. These organs remained histologically normal.

\section{Methylprednisolone Circulating Half-life}

Serial serum levels of methylprednisolone were measured in 13 dogs during the 24 hours after administration of a pulse. A high mean

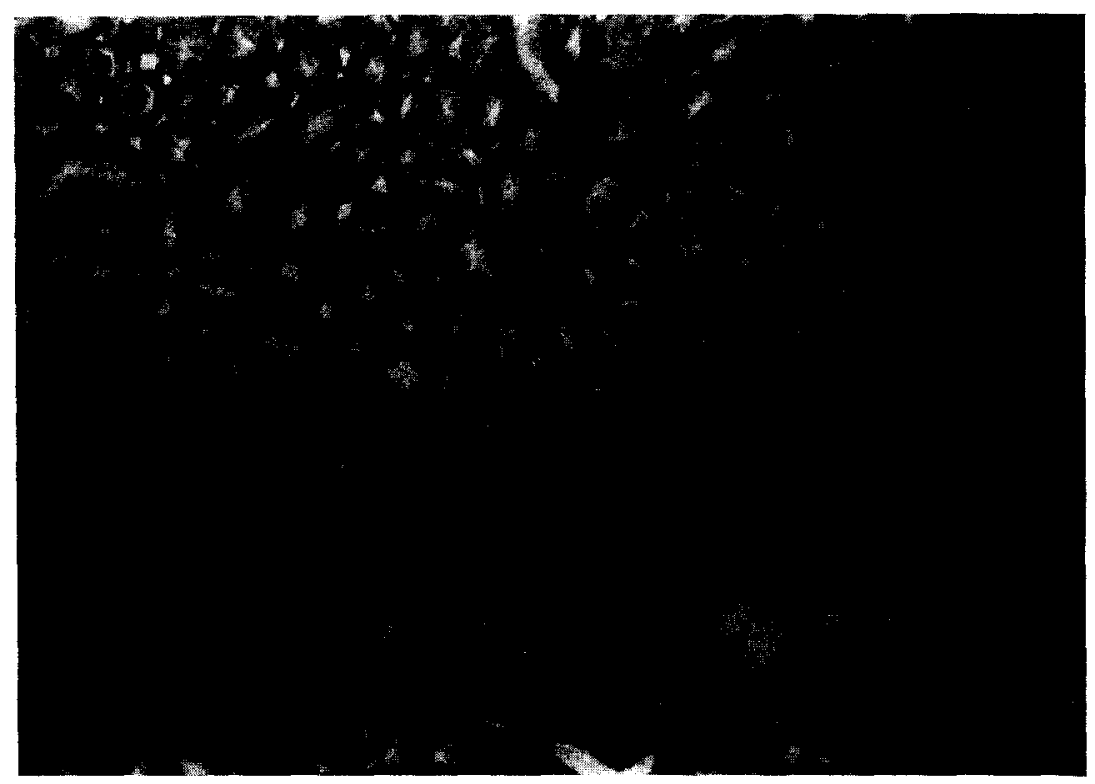

Fig. 1. Section of kidney (No. SMH-9) at the time of transplantation exbibiting no significant inflammatory cellular infiltrate. (Methyl green pyronin stain, $\times 112$ ). 


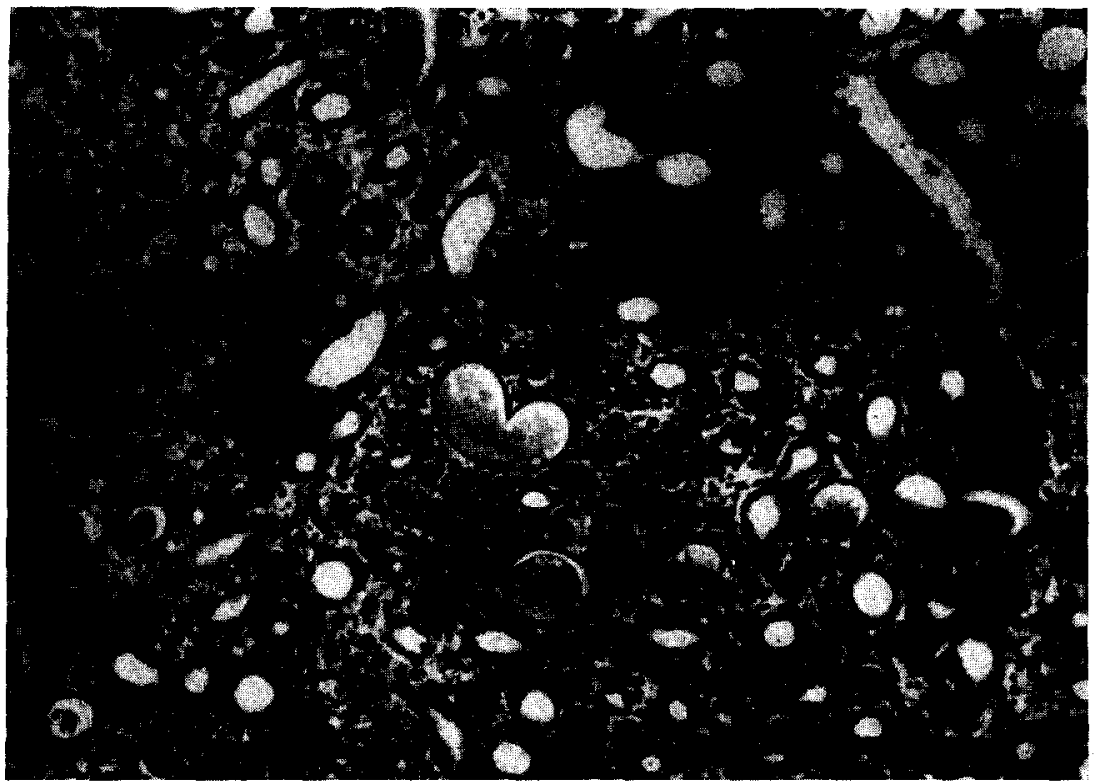

Fig. 2. Section of kidney (No. SMH-9) 5 days after transplantation and immediately prior to methylprednisolone pulse showing an intense, diffuse cellular infiltrate. Much of this infiltrate is composed of pyroninophilic cells. (Methyl green pyronin stain, $\times 112$ ):

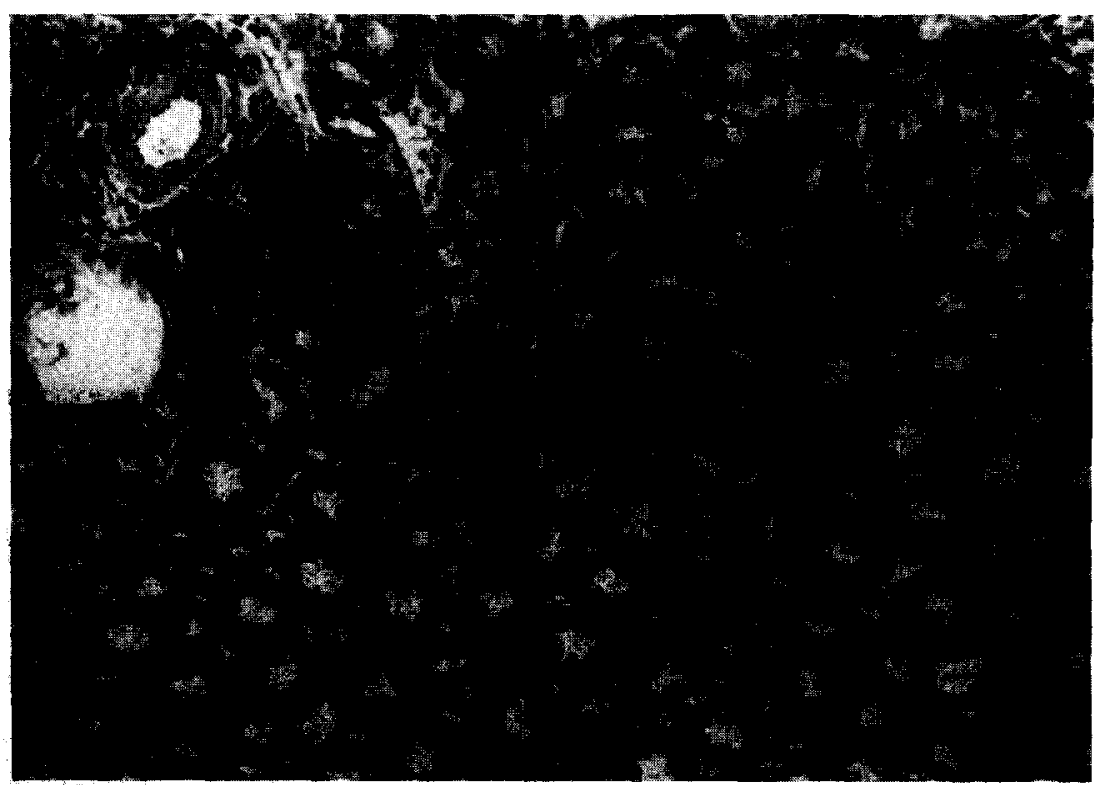

Fig. 3. Section of kidney (No. SMH-9) 48 hours after methylprednisolone pulse showing an aggregate of pyroninophilic cells around a blood vessel. The cellular infiltrate is much less diffuse than depicted in Fig. 2. The reduction in pyroninophilie cells is better appreciated in the original color slides. (Methyl green pyronin stain, $\times 112$ ).

peak blood level of $1415 \pm 679 \mu \mathrm{g} / 100 \mathrm{ml}$. was reached immediately after administration of the pulse (Table 5). The mean circulating half-life was $3.48 \pm 0.70$ hours. The very high mean correlation coefficient of $-0.93 \pm 0.06$ when serial levels were correlated with time suggests that methylprednisolone is metabolized by a first-order reaction (Fig. 4).

\section{Autopsies}

Gross evidence of rejection was obvious in all renal allografts at autopsy. The grafts werc 
swollen, edematous, and hemorrhagic; areas of necrosis within the renal parenchyma were present and frequently the renal vessels were thrombosed. In several dogs purulent exudate was present at the renal biopsy sites. A special effort was made to identify possible toxic manifestations of steroid pulse therapy but none were found. In no dogs was gastrointestinal bleeding, gastric or intestinal ulcerations, or pulmonary infections demonstrated.

\section{Human Experience}

Ninety-eight episodes of acute rejection were identified in 100 consecutive renal allotransplant recipients. In 90 of these episodes, or $92 \%$ of the time, the rejection process was either halted or reversed with pulse therapy. Most of the paticnts reccived more than one pulse, but on several occasions rejection was promptly reversed with a single pulse. No complications occurred which could be attributed to this therapy.

\section{Discussion}

The most common method used to treat acute rejection of renal allografts is to temporarily increase the dose of corticosteroids. Lsually corticosteroids are administered orally in two or three divided doses each day. Other means to treat rejection, such as the use of local radiation therapy or administration of

Table 5. Circulating Half-life of Methylprednisolone in 13 Dogs

\begin{tabular}{cccc}
\hline Dog & $\begin{array}{c}r \\
\text { (Correlation } \\
\text { Coefficient) }\end{array}$ & $\begin{array}{c}\text { Peak Level } \\
(\mu \mathrm{g} .) / 100 \\
\mathrm{ml} .)\end{array}$ & $\begin{array}{c}t_{1 / 2} \\
\text { (hours) }\end{array}$ \\
\hline 1 & -0.98 & 1301 & 3.83 \\
2 & -0.99 & 2169 & 3.04 \\
3 & -0.99 & 1644 & 3.52 \\
4 & -0.96 & 2233 & 3.54 \\
5 & -0.96 & 434 & 3.47 \\
6 & -0.93 & 2282 & 3.04 \\
7 & -0.83 & 1489 & 2.56 \\
8 & -0.95 & 1528 & 4.15 \\
9 & -0.86 & 335 & 4.41 \\
10 & -0.99 & 1716 & 2.53 \\
11 & -0.89 & 1306 & 4.88 \\
12 & -0.95 & 409 & 3.18 \\
13 & -0.85 & 1219 & 3.03 \\
Mean & -0.93 & 1415 & 3.48 \\
SD & \pm 0.06 & \pm 679 & \pm 0.70 \\
\hline
\end{tabular}

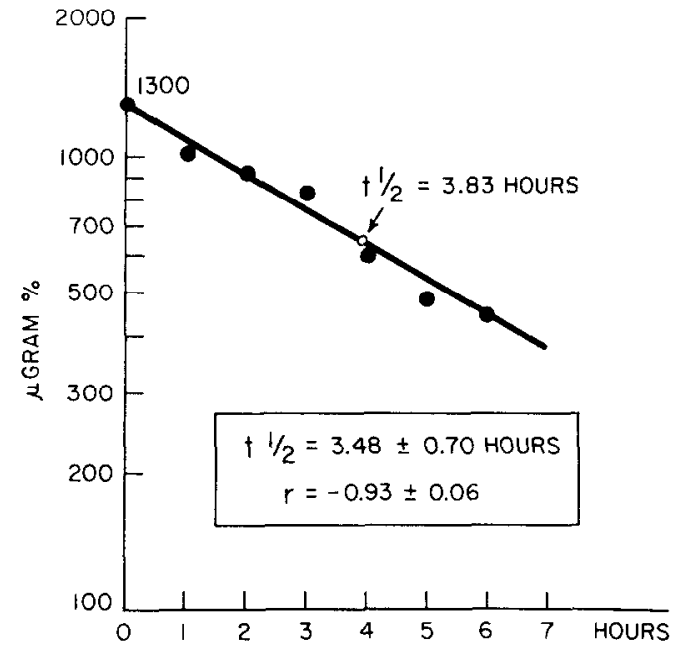

Fig. 4. Circulating half-life of methylprednisolone in 13 Dogs. The graph illustrates as an example serial serum levels of methylprednisolone and the half-life as determined in dog No. SMH-1. In the box below are indicated the mean half-life and mean correlation coefficient for 13 dogs.

antilymphocyte globulin, are probably less effective and have been used only as adjuncts. Unfortunately, current methods to reverse rejection are not always successful and the use of high doses of corticosteroids is frequently associated with significant complications. Indeed, it has been common for recipients of renal allografts to die from complications secondary to immunosuppressive therapy, even though rejection is controlled [11].

The use of large intravenous doses of corticosteroids for reversing rejection has several potential advantages. A maximal circulating concentration of the drug can be achieved promptly. If the intravenous dose is administered intermittently, that is every 2 or 3 days, many of the toxic side effects of corticosteroids might be avoided. This would be especially true if it could be proved that the half-life of the particular corticosteroid utilized was relatively short. Considerable clinical evidence exists from experience gained in the treatment of other diseases that intermittent administration of corticostcroids, that is every second or third day, is associated with fewer side effects while therapeutic effectiveness is maintained $[8,10]$. Despite these potential advantages the question of the effectiveness of such a regimen for reversing rejection has not been verified. Only a few transplant teams have reported experi- 
ence with intermittent pulse therapy to treat rejection, and little experimental evidence is available $[2,4]$.

The half-life of methylprednisolone in dogs was demonstrated to be relatively short, that is, $31 / 2$ hours, and a high maximum concentration was immediately achieved. The gas chromatographic method used to determine serum levels of methylprednisolone is specific and reproducible [1]. Coburg et al. demonstrated that the half-life of prednisolone is also relatively short in dogs [4]. However, they utilized the Porter-Silber chromagen technique which is less specific than gas chromatography. Collins et al. demonstrated that after oral administration of prednisolone the peak serum level is usually not reached for 1-2 hours, and the peak level is frequently only one-half the level reached with $I-V$ administration of an equivalent dose [5].

When used alone there is little evidence that corticosteroids are able to consistently prevent rejection in dogs. Zukosky et al. were able to prolong survival of canine renal allografts by administering $30 \mathrm{mg}$. of prednisone per day [12]. On the basis of most investigators' experience the administration of a single dose of corticosteroids might not be expected to have much influence on the rejection process. However, we felt that if rejection could be modified using a single dose of corticosteroids, this would be the most easily interpretible evidence that pulse therapy might be effective. A variation in response was expected because of the antigenic disparity betwcen donor and recipient in an outbred population of dogs, and the impossibility of consistently identifying the same stage of rejection for administering pulse therapy to different animals. The reductions in serum and urine LDH and increases in urine volume and osmolality observed in most dogs, and the reduction in cellular infiltrates seen histologically in two dogs are good biologic evidence that a single pulse does modify rejection. These changes occurred despite the fact that rejection was quite advanced at the time of pulse therapy in our experimental animals. There was no evidence of a spontaneous tendency for rejection to reverse in untreated animals in this study and in other experiments in our laboratory.
The dog treated with four consecutive pulses is especially interesting to us, but since only a single experiment of this type was performed, additional studies are needed for confirmation. A reduction in cellular infiltrate was not seen until 8 days after transplantation, and after the dog had received three pulses. This suggests that more than one pulse would be required to more consitently demonstrate a histologic reduction in cellular infiltrate. The absence of side-effects in this and the other dogs in the experiment that received methylprednisolone intravenously is somewhat surprising since this species is known to be quite sensitive to the toxic effects of corticosteroids. This lack of side effects is probably related to the short half-life of methylprednisolone.

Kountz et al. and Bell et al. have used intravenous corticosteroids to reverse rejection in humans $[2,6]$. Their favorable transplant survival figures indicate that this therapy is effective. They have utilized 1 gram of methylprednisolone and Kountz has combined this therapy with other drugs such as heparin or actinomycin D. We have used approximately twice the dose of methylprednisolone as these investigators to treat rejection and have not added any adjunctive therapy. In our elinical experience rejection was reversed more than $90 \%$ of the time with single or multiple pulses as required. No significant side effects occurred. A comparative study would be required to determine the ideal dose of intravenous corticosteroids to reverse rejection.

\section{Summary}

Intravenous administration of large doses of methylprednisolone sodium succinate was demonstrated to modify rejection in both canine and human renal allografts. One dose of intravenous methylprednisolone $30 \mathrm{mg} . / \mathrm{kg}$. administered during acute rejection in dogs resulted in an increase in urine volume and osmolality, and a decrease in serum and urine $\mathrm{LDH}$. In two dogs treated with a single dose and in one dog treated with four consecutive daily doses histologic evidence of reversal of rejection with reduction of cellular infiltrate was achieved. Ninety-two percent of rejections encountered in 100 consecutive human recipi- 
ents of renal allografts were halted or reversed with intravenous methylprednisolone $30 \mathrm{mg}$./ $\mathrm{kg}$. given every 48-72 hours to a maximum of three or four doses. No significant side effects were observed either in dogs or humans with this therapy. The mean circulating half-life of intravenous methylprednisolone was determined to be $3.48 \pm 0.7$ hours in dogs. Intermittent intravenous administration of methylprednisolone has the potential advantage of being associated with fewer side effects than frequent oral administration and has been shown to be an effective method for modifying rejection.

\section{REFERENCES}

1. Bacon, G. E. Measurement of plasma prednisolone by gas chromatography. J. Lab. Clin. Med. 73: $1030,1969$.

2. Bell, P. R. F., Briggs, J. D., Colman, K. C., Patan, A. M., Wood, R. F. M., MacPherson, S. G., and Kyle, K. Reversal of acute clinical and experimental organ rejection using large doses of intravenous prednisolone. Lancet $1: 876,1971$.

3. Berger, L., and Broida, D. The colorimetric determination of lactic dehydrogenase in serum, urine, or other fluids. Sigma Technical Bulletin,
Sigma Chemical Company, St. Louis, 1969. No. $500, \mathrm{p} 1$.

4. Coburg, A. J., Gray, S. H., Katz, F. H., Penn, I., Halgrimson, C., and Starzl, T. E. Disappearance rates and immunosuppression of intermittent intravenously administered prednisolone in rabbits and human beings. Surg. Gynec. Obstet. 131:933, 1970.

5. E. J. Collins, Project 20,000-1 Report E-90-56. pages 18 and 30 . (Unpublished data).

6. Kountz, S. L., and Cohn, R. Initial treatment of renal allografts with large intrarenal doses of immunosuppressive drugs. Lancet $1: 338,1969$.

7. Lillie, R. D. Histopathologic Technique and Practical Histochemistry, 3rd. ed., p 152. New York: McGraw-Hill, 1965.

8. MacGreger, R. R., Sheagren, J. N., Lipsett, M. B., and Wolff, S. M. Alternate-day prednisone therapy. New Eng. J. Med. $280: 1427,1969$.

9. Novak, E., Stubbs, S. S., Seckman, C. F., and Hearron, M. S. Effects of a single large intravenous dose of methylprednisolone sodium succinate. Clin. Pharmacol. Ther. $11: 711,1970$.

10. Soyka, L. F., and Saxena, K. M. Alternate-day steroid therapy for nephrotic children. J.A.M.A., $192: 125,1965$.

11. Starzl, T. E. Experience in Renal Transplantation. Philadelphia: Saunders, 1964.

12. Zukosky, C. F., Callaway, J. M., and Rhea, W. $\mathrm{G}$. Tolerance to a canine renal homograft induced by prednisolone. Surg. Forum. 14:208, 1963. 